\title{
Assessing the Impacts of Climate Change and Variability on Maize (Zea mays) Yield over Tanzania
}

\author{
Amina Abdalla Lukali', Sarah E. Osima1, Yunsheng Lou'², Kombo Hamad Kai' \\ ${ }^{1}$ Tanzania Meteorological Authority (TMA), Kisauni, Zanzibar, TMA Ubungo Plaza, Dar es Salaam, Tanzania \\ ${ }^{2}$ Depertment of Applied Meteorology, Nanjing University of Information Science and Technology, Nanjing, China \\ Email: amina.lukali@meteo.go.tz,sarah.osima@gmail.com,kombo.kai@meteo.go.tz
}

How to cite this paper: Lukali, A.A., Osima, S.E., Lou, Y.S. and Kai, K.H. (2021) Assessing the Impacts of Climate Change and Variability on Maize (Zea Mays) Yield over Tanzania. Atmospheric and Climate Sciences, 11, 569-588.

https://doi.org/10.4236/acs.2021.113035

Received: March 10, 2021

Accepted: July 9, 2021

Published: July 12, 2021

Copyright $\odot 2021$ by author(s) and Scientific Research Publishing Inc. This work is licensed under the Creative Commons Attribution International License (CC BY 4.0).

http://creativecommons.org/licenses/by/4.0/

\begin{abstract}
This study aimed at understanding the impacts of the seasonal hydroclimatic variables on maize yield and developing of statistical crop model for future maize yield prediction over Tanzania. The food security of the country is basically determined by availability of maize. Unfortunately, agriculture over the country is mainly rain fed hence highly endangered by the detrimental consequences of climate change and variability. Observed climate data was acquired from Tanzania Meteorological Authority (TMA) and Maize yield data from Food and Agriculture Organization (FAO). The study used the Mann-Kendall test and Sen's slope for trend and magnitude detection in minimum, maximum temperature and rainfall at the $95 \%$ confidence level. The results have shown that rainfall is decreasing over the country and especially during the growing season but increasing during short rains season. Characteristics of seasonal climatic variables, cycle during growing period were linked to maize yield, and high (low) yield was reported during anomalous wet (dry) growing seasons. This portrays seasonal dependence of maize production. Statistical crop model was built by aggregating spatial regions that have statistically significant relation with maize yield. Results show that, $58.8 \%$ of yield variance is linked to seasonal hydroclimate variability. Rainfall emerged as the dominant predictor variable for maize yield since it accounts for $44.1 \%$ of yield variance. The modeled and observed yields exhibit statistically substantial relationship $(r=0.78)$ hence depicting high credence of the built statistical crop model. Also, the results revealed a decreasing trend in Maize yield with further Lessing trend is projected to proceed in the future. This calls for adaptation and implementation of appropriate regional measures to raise maize production in order to feed the burgeoning human population amidst climate change.
\end{abstract}




\section{Keywords}

Rainfall, Temperature, Climate Variability, Maize Yield, Maize Yield Projections Tanzania

\section{Introduction}

Studies have shown changes and variability in both temperature and rainfall distributions and amount in the Greater Horn of Africa and Tanzania inclusive. The projected climate under global warming level $1.5 / 2^{\circ} \mathrm{C}$ shows both changes and the increase and decrease of length of dry and wet spells [1]. The agricultural sector is subject to climate variability, particularly the inter-annual variability of temperature, rainfall patterns, and extreme weather events (droughts and floods) [2]. In the previous year, 2020 the country experienced very heavy rainfall, which was associated with widespread floods [3]. The occurrences of these climate events are expected to surge in the future and have a detrimental impact on the agricultural sector more specifically rain-fed agriculture [4] [5] [6] [7]. These impacts are negative in some areas, positive in others, and change over time [8]. Maize production is an important agricultural activity in Tanzania and is also the main economic driver [9]. As a food crop, maize is very important in the tropics, as it is suitable for short-term crop intercropping. Reference [10] has noted that, Maize provides $42 \%$ of dietary nutritional value and it is one of the crucial sources of calories. The crop is also ranked number two after wheat in terms of importance [11]. About $80 \%$ of the maize growing zones consist of small-scale farmers who produce maize both for cash and as a subsistence crop [12]. Agriculture in Tanzania is mainly rain-fed hence highly impacted by changes in climate.

Due to the location of East Africa, climate (rainfall and temperature) are the main source of crop predictor [13] [14]. The region has severe foot prints of the impacts of climate change on food security, which is measured in terms of accessibility, availability, stability and utilization [15]. Meeting this criterion has remained a global challenge due to burgeoning human population on the background of climate change.

There are several ways in which maize production is affected by climate change, prevalence of pest and diseases, changes in technology, and farm management. For example, increase of temperature above certain thresholds for different crops it leads to agricultural drought as the crop suffers from water stress [16]. This may also change the growth length of the crop (from sowing to maturity) as it leads to increased rate of photosynthetic stress hence leading to decreased yield. Additionally, rainfall variability status within a season [17], changes in extreme rainfall events, and prolonged drought during the growing season [18] might have great impacts on crop production and yields. Notably, the time of occurrence of either heat or water stress is crucial in determining the extent of the 
impacts it will have on the crop.

There is lack of information on the impacts of climate change and variability on national maize yield in the recent past. Previous studies over the study domain have reported to have considerable knowledge gap on the aggregated location-wise impacts of climate change on the national maize yield which is crucial in determining the national food security programme and hence the essence of this study. Thus, this study aimed at: 1) analyzing the spatial and temporal variability of seasonal and annual climate parameters including rainfall, maximum, and minimum temperature over Tanzania; 2) determining the relationship between high/low maize yield with the associated climate anomalies; 3) To build a statistical crop model between maize yield and climate indices (rainfall, maximum and minimum temperature). Other factors that affect maize yield which includes pests and disease invasion, changes in technology, damages of the crop by animals, use of the fertilizers, and changes in farming methods beyond the scope of this study.

\section{Data and Methodology}

\subsection{Study Area}

Tanzania (Figure 1) is located in Eastern Africa between latitudes $1^{\circ} \mathrm{S}$ and $12^{\circ} \mathrm{S}$ and longitudes $29^{\circ} \mathrm{E}$ and $41^{\circ} \mathrm{E}$. The country has two rainfall regimes (i.e. the unimodal and bimodal). The areas characterized by bimodal regime have two rainy seasons, the long rainy season (March, April, and May) (MAM) traditionally called Masika rains and the short rainy season (October, November, and December) (OND) traditionally called Vuli rains. The seasonal rainfall patterns

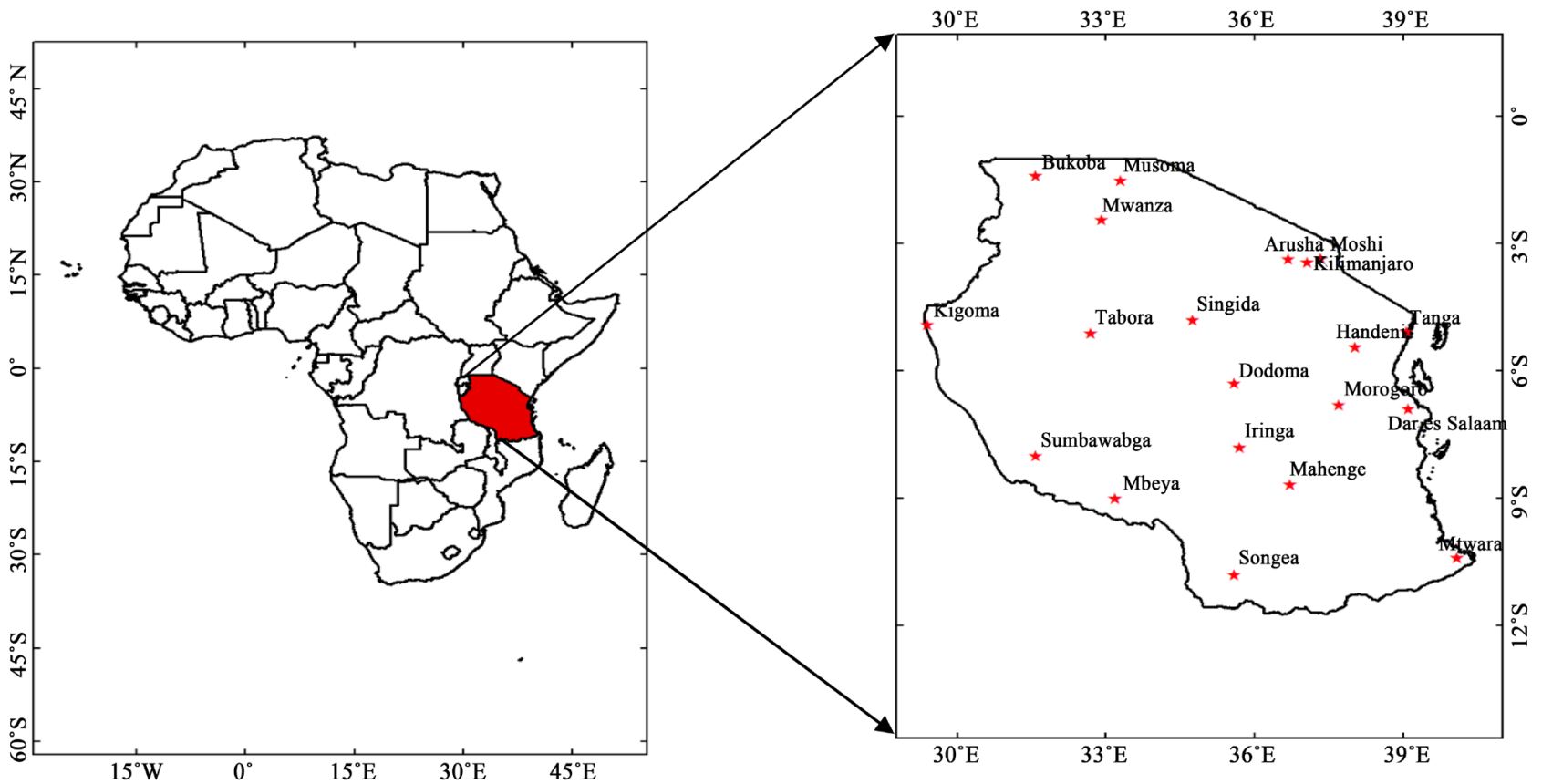

Figure 1. Map of Africa (left) showing the geographical location of Tanzania and Map of Tanzania (right) showing station used in the study. 
are determined by northwards and southwards movement of the Inter-Tropical Convergence Zone (ITCZ). The northwards migrating of the ITCZ, brings MAM seasonal rainfall and as it returns (i.e. southwards movement), the country receives OND seasonal rainfall [19] [20].

The long rain season produces heavier and long duration rain and exhibits lower inter annual but large spatial variability [21], the characteristics that are attributed to the local factors dominating over the large-scale factors. In contrast to MAM, rainfall events during the short rain season are less intense, short-lived, and show stronger inter-seasonal and inter-annual variability. The short rainy seasons exhibits spatial homogeneity, a characteristic that is associated with largescale phenomenon such as El Niño-southern oscillation (ENSO) [22]. The country experiences the same bimodal pattern of temperature distribution as rainfall. The annual average temperature ranges from $25^{\circ} \mathrm{C}-32^{\circ} \mathrm{C}$ [23].

\subsection{Data}

\section{Preliminary Analysis}

The 30 years (1988-2017) Climate data of monthly rainfall (mm), minimum, and maximum temperature $\left({ }^{\circ} \mathrm{C}\right)$ were collected from TMA headquarters located at Dar es Salaam for 20 synoptic stations. The spatial distribution of these stations is illustrated in Figure 1. Maize yield data (tons/hectare) was acquired from FAO Corporate Statistical Database. Table 1 shows the list of stations used and their geographical characteristics.

\subsection{Methodology}

Understanding current trend in hydroclimate variables in crucial in determine the expected agricultural yields. Mann-Kendall test was used to understand the hydroclimatic trend. The usage of this method is impaired by presence of autocorrelation in the dataset; hence autocorrelation was tested by use of acf () and pacf () commands in R Studio. If the time series of the datasets exhibit autocorrelation, modified Mann-Kendall was used. The level of significance used in this study was 0.05 , and the trends were considered significant when $\alpha$-value was less than or equal to 0.05 . The preliminary analysis was carried out on the data to test the homogeneity of annual rainfall using Standard Normal Homogeneity Test (SNHT) at a 95\% confidence level (Table 1). This method was adopted from [24]. Seasonal averages of the climate variables were obtained by averaging monthly data, which was available.

The choice of using maize crop in this study was based on the significance of crop to food security in the country, the number of calories produced by the crop and how many people depend on the crop. In East Africa (EA) the main source of calories is coffee, sorghum, and maize with $3.1 \%, 8.6 \%$, and $27.1 \%$, respectively [25]. Maize yield is highly dependent on seasonal weather parameters during the growing period than non-growing [14] [26] [27]. These seasonal climate indices are mainly rainfall and temperature that have been documented to 
Table 1. List of stations and their corresponding elevation.

\begin{tabular}{|c|c|c|c|c|c|c|}
\hline No. & Station names & $\begin{array}{l}\text { Latitude } \\
\qquad(S)\end{array}$ & $\begin{array}{l}\text { Longitude } \\
\qquad(E)\end{array}$ & $\begin{array}{l}\text { Elevation } \\
\quad(m)\end{array}$ & $\begin{array}{l}\text { Total Annual } \\
\text { rainfall }(\mathrm{mm})\end{array}$ & SNHT \\
\hline 1 & Arusha & $3^{\circ} 22^{\prime}$ & $36^{\circ} 38^{\prime}$ & 1372 & 763.72 & 0.91 \\
\hline 2 & Bukoba & $1^{\circ} 20^{\prime}$ & $31^{\circ} 49^{\prime}$ & 1144 & 2003.89 & 0.17 \\
\hline 3 & Dar es Salaam & $6^{\circ} 52^{\prime}$ & $39^{\circ} 12^{\prime}$ & 53 & 1070.7 & 0.11 \\
\hline 4 & Dodoma & $6^{\circ} 10^{\prime}$ & $35^{\circ} 46^{\prime}$ & 1120 & 571.24 & 0.31 \\
\hline 5 & Kilimanjaro & $3^{\circ} 25^{\prime}$ & $37^{\circ} 40^{\prime}$ & 891 & 505.76 & 0.92 \\
\hline 6 & Kigoma & $4^{\circ} 53^{\prime}$ & $29^{\circ} 40^{\prime}$ & 822 & 943.67 & 0.25 \\
\hline 7 & Mbeya & $8^{\circ} 56^{\prime}$ & $33^{\circ} 28^{\prime}$ & 1758 & 920.18 & 0.59 \\
\hline 8 & Morogoro & $6^{\circ} 50^{\prime}$ & $37^{\circ} 39^{\prime}$ & 526 & 805.69 & 0.67 \\
\hline 9 & Moshi & $3^{\circ} 21^{\prime}$ & $37^{\circ} 20^{\prime}$ & 813 & 807.89 & 0.39 \\
\hline 10 & Mtwara & $10^{\circ} 21^{\prime}$ & $40^{\circ} 11^{\prime}$ & 113 & 1075.12 & 0.61 \\
\hline 11 & Musoma & $1^{\circ} 30^{\prime}$ & $33^{\circ} 48^{\prime}$ & 1147 & 887.31 & 0.34 \\
\hline 12 & Mwanza & $2^{\circ} 28^{\prime}$ & $32^{\circ} 55^{\prime}$ & 1140 & 1136.76 & 0.42 \\
\hline 13 & Songea & $10^{\circ} 40^{\prime}$ & $35^{\circ} 35^{\prime}$ & 1036 & 1019.94 & 0.54 \\
\hline 14 & Tabora & $5^{\circ} 5^{\prime}$ & $32^{\circ} 50^{\prime}$ & 1182 & 937.13 & 0.53 \\
\hline 15 & Tanga & $5^{\circ} 5^{\prime}$ & $39^{\circ} 40^{\prime}$ & 39 & 1221.08 & 0.3 \\
\hline 16 & Singida & $4^{\circ} 8^{\prime}$ & $34^{\circ} 72^{\prime}$ & 1307 & 688.1 & 0.98 \\
\hline 17 & Iringa & $7^{\circ} 63^{\prime}$ & $35^{\circ} 77^{\prime}$ & 1428 & 609.8 & 0.34 \\
\hline 18 & Handeni & $5^{\circ} 43^{\prime}$ & $38^{\circ} 03^{\prime}$ & 756 & 808.19 & 0.56 \\
\hline 19 & Sumbawanga & $7^{\circ} 97^{\prime}$ & $31^{\circ} 60^{\prime}$ & 1923 & 843.7 & 0.1 \\
\hline 20 & Mahenge & $8^{\circ} 67^{\prime}$ & $36^{\circ} 72^{\prime}$ & 1200 & 1936.6 & 0.69 \\
\hline
\end{tabular}

independently influence the crop yield by 3 or 4 times more than solar radiation. The First Differencing Method was deployed on maize yield in order to remove other factors that influence maize yield and were not considered in this study [28].

\subsubsection{Trend Analysis}

\section{1) Mann-Kendall Test}

The Mann-Kendall (MK) trend test is a non-parametric statistical method that is used to capture the trend in data over time. The test observes whether a random response variable monotonically rises or falls with time [29].

The Standardized Mann-Kendall test statistic is given as follows;

$$
S=\sum_{i=1}^{n-1} \sum_{j=i+1}^{n} \operatorname{sgn}\left(x_{j}-x_{i}\right)
$$

where $S$ is a statistic, $x_{i}$ and $x_{j}$ are the sequential data values, $n$ is the distance of the time series, and $\operatorname{sgn}\left(x_{j}-x_{i}\right)$ is clarified as;

$$
\operatorname{sgn}\left(x_{j}-x_{i}\right)= \begin{cases}1 & \text { if } x_{j}>x_{i} \\ 0 & \text { if } x_{j}=x_{i} \\ -1 & \text { if } x_{j}<x_{i}\end{cases}
$$


In the monotonic trend test, we need to test the null hypothesis $\left(\mathrm{H}_{0}\right)$ of no trend or the alternative hypothesis, $\mathrm{H}_{1}$, where there is rise or fall monotonic trend [30]. Positive $(+)$ values specify a rise over time while, negative $(-)$ values indicate descend [29]. Since the data is independent and normally distributed, the variance of the $\mathrm{S}$ statistic $(\operatorname{Var}(S))$ is identified by;

$$
\operatorname{Var}(S)=\frac{n(n-1)(2 n+5)}{18}
$$

The values of $S$ and $\operatorname{Var}(S)$ are used to compute the test statistic " $Z$ " as follows:

$$
Z= \begin{cases}\frac{S-1}{\sqrt{\operatorname{Var}(S)}} & \text { if } S>0 \\ 0 & \text { if } S=0 \\ \frac{S+1}{\sqrt{\operatorname{Var}(S)}} & \text { if } S<0\end{cases}
$$

The $Z$ value is used to calculate the statistically significant trend. A positive or negative value of $Z$ represents a rise or fall trend, respectively. The null hypothesis is excluded at the significance level of $\alpha$ if $|Z| \geq Z_{\alpha / 2}$, where $Z_{\alpha / 2}$ is the critical value of the standard normal distribution with a probability exceeding $\alpha / 2$, and it shows that the trend is significant. If $|Z|<Z_{\alpha / 2}$, the null hypothesis is recognized, and the trend is not significant. A trend is examined to be statistically significant if $\alpha \leq 0.05$ or $\geq 95 \%$ level [31].

\section{2) Sen's Slope Estimator (SSE)}

This method was used to find the magnitude of the considered trend in a certain time series [32]. It is usually applied when the assessed slope is measured to be linear. This is demonstrated exactly as;

$$
S S E_{i}=\frac{x_{k}-x_{l}}{k-l} \text { for } i=1, \cdots, n
$$

where $i$ is the number of the time steps, $x_{k}$ and $x_{l}$ are the data points at point $k$ and $I$ respectively. In this case, $k$ must be larger than $l$.

In the case of only one datum in each period, then $n$ can be explained as $n=n(n-1) / 2$.

When there are multiple data in one or more-time periods, then,

$$
n<n(n-1) / 2 \text {. }
$$

where $n$ characterize the time steps. The $n$ values of $S S E$ are organized from lowest to highest and then the Sen's slope estimator is defined as;

$$
Q_{\text {med }}= \begin{cases}S S E_{(N+1) / 2} & \text { when } n \text { is an odd number } \\ \frac{S S E(N / 2)+\operatorname{SSE}(N+1 / 2)}{2} & \text { when } n \text { is an even number }\end{cases}
$$

The trend is specified by the sign of the $Q_{\text {med }}$ while its value portrays the degree of the slope. The confidence interval of the $Q_{\text {med }}$ at certain probability is then acquired to examine if the slope is statistically significant at zero. The con- 
fidence interval of the considered gradient is exposed in Equation (7) [33] [34].

$$
C_{\alpha}=\frac{Z_{1-a}}{2} \sqrt{\operatorname{VarS}}
$$

where, the variance of the $S$ statistic $(\operatorname{Var}(S))$ is demonstrated in Equation (3). $Z_{1-a / 2}$ is the tabulated value obtained from the $t$-table. According to [33], the lower and upper limits levels of the significant bands, $Q_{\max }$ and $Q_{\min }$, are $M_{1}^{\text {th }}$ largest and the $\left(M_{2}+1\right)^{\text {th }}$ largest of the $N$ ordered slope estimates. In this case, $M_{1}=\frac{N-C_{a}}{2}$ and $M_{2}=\frac{N+C_{a}}{2}$. In this study, the slope will be measured statistically significant at $(\alpha=0.01)$ and if the two limits $Q_{\min }$ and $Q_{\max }$ have same sign.

\subsubsection{Statistical Crop Model}

In order to predict the expected yearly maize yield for future food secure country, a multiple linear regression model was built based on the seasonal climate indices of the growing period and regions which have significant influence on the annual maize yield. Indeed, Pearson correlation method and t-test at $95 \%$ significance level was used to classify the region where climate stress has significant impacts on maize yield. The correlation was amid climate indexes anomalies (rainfall, minimum, and maximum temperature) and the maize yield anomalies at each region represented by the synoptic station.

The climate indexes for building the multi linear regression model was obtained by averaging the climate indexes for all regions with statistically significant correlation coefficient (positive or negative). Mathematically, the multi linear -regression model can be expressed as:

$$
Y(t)=\beta_{0}+\beta_{1} x_{1}(t)+\cdots+\beta_{n} x_{n}(t)+\varepsilon
$$

where $y(t)$ is the maize yield in year $t(t=1,2,3, \cdots, 20)$,

$n=$ denotes the number of climate index used, $x_{1}, x_{2}, \cdots, x_{n}$ represented the seasonal hydroclimate variables in region that has statistically significant correlations coefficient. $\beta_{0}=y$-intercept and $\varepsilon=$ Error term.

Notably, since multicollinearity inflates the explained variance, it was tested using variance Inflation Factor and all the variable considered did not significantly correlate with each other.

\subsection{Correlation Method}

Person correlation coefficient $\left(r_{x y}\right)$ method is widely used by many researchers in similar types of research [28]. Mathematically, assuming we have a series of $n$ measurements $X$ and $Y$ written as $x_{i}$ and $y_{i}$ where by $i=1,2, \cdots, n$, then $\left(r_{x y}\right)$ can be used to approximate the kind of relationship between $X$ and $Y$ exhibits. The correlation value $r_{X Y}$ is bounded by $[1-1]$ i.e. $-1 \leq r_{x y} \leq 1$. The positive $r_{X Y}$ means that as one variable increases the others increases and the vice versa is true (direct relation). Inverse relation exhibits when an increase of one variable is accompanied by a corresponded decrease in the other variable. 
The sample correlation can be written as

$$
r_{x y}=\frac{\sum_{i=1}^{n}\left(x_{i}-\bar{x}\right)\left(y_{i}-\bar{y}\right)}{\sqrt{\sum_{i=1}^{n}\left(x_{i}-\bar{x}\right)^{2} \sum_{i=1}^{n}\left(y_{i}-\bar{y}\right)^{2}}}
$$

where by, $\bar{y}$ is the mean maize yield, $\bar{y}$ is the mean of the parameter in considerations, $y_{i}$ is the annual maize yield and $n$ is the distance of the time series.

The strength of the relationship was evaluated using student t-test, if the calculated $t$ value was less than the tabulated value at $n-2$ degree of freedom, then the value was considered significant.

$$
t=r_{x y} \sqrt{\frac{n-2}{1-r_{x y}^{2}}}
$$

whereby, $r_{x y}$ is the correlation coefficient and $n-2$ is the degree of freedom.

\section{Results and Discussion}

\subsection{Spatial Distribution of Seasonal and Annual Temperature and Rainfall}

The results of the trends analysis from the MK test were categorized into two groups i.e. increasing (positive) and decreasing (negative) trends. The seasonal analysis of rainfall data for all stations (Figure 2) exhibited that there are both negative and positive trends during long and short rain seasons, as well as on annual scale. Moreover, results indicate that, during MAM season, 19/20 stations revealed a decreasing trend, while one station (Sumbawanga) has a significant negative trend. However, Bukoba around the Lake Victoria basin depicted insignificant positive trends in both seasons (Figure 2(a)). Generally, results reveal that MAM seasonal rainfall is decreasing. The implication of the decrease in MAM rainfall trend is to endanger the economy because MAM is considered as the main crop growing season for rain-fed agriculture in Tanzania.
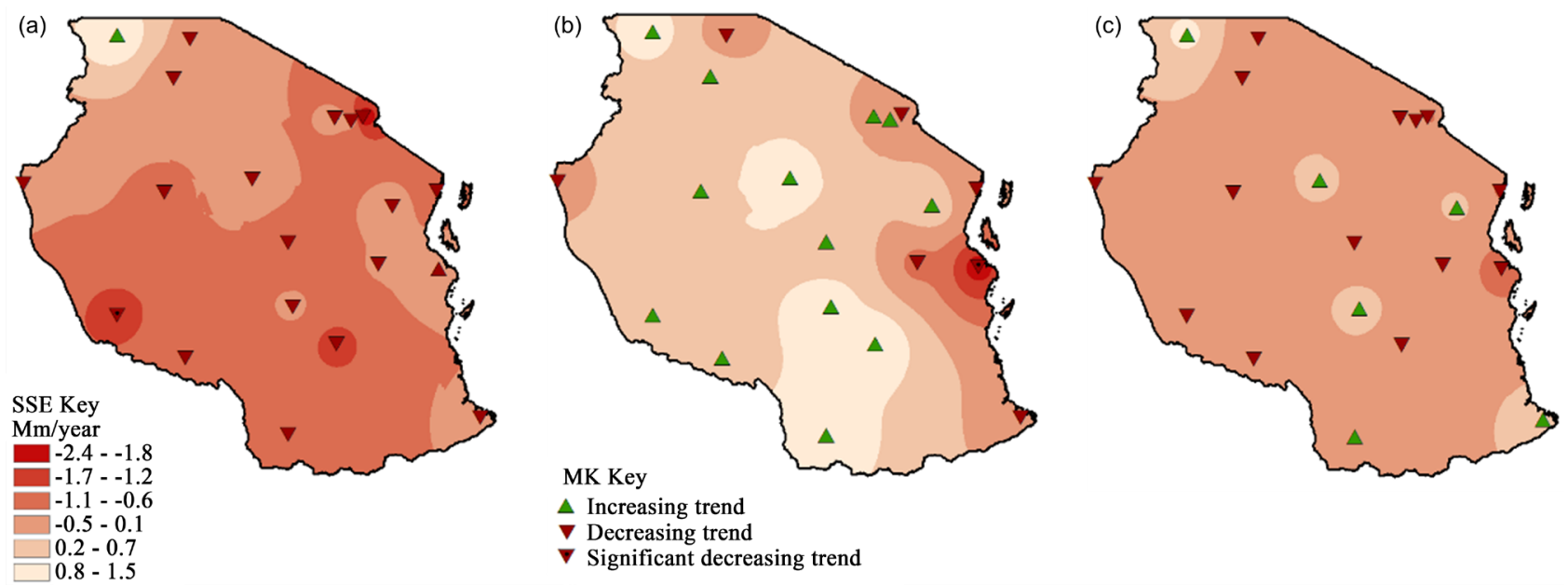

Figure 2. Spatial distribution of rainfall trend from 1988 to 2017; for (a) MAM (b) OND, and (c) annual scale. The red (green) triangles display a decreasing (increasing) trend, whereas the center dotted characterizes a significant trend at $95 \%$ confidence level. The background color shows the rainfall magnitude. 
On the other hand, 13/20 of the synoptic stations reported increasing trend during short rainy season, while the remaining seven (7) stations recorded a decreasing trend, in which Dar es Salaam had a significant lessen in rainfall with a magnitude of $-2.05 \mathrm{~mm} /$ year. This implies that, Tanzania is becoming wetter in this season as most of the stations exhibits an increase trend with a magnitude of up to $1.3 \mathrm{~mm} /$ year i.e. Mahenge station. As for the annual rainfall, results show that $14 / 20$ stations observed an insignificant negative trend, while six stations recorded insignificant positive trend. Conclusively, this ongoing rainfall trend is not favorable for optimizing agriculture over the country which is least supplemented by irrigation.

Generally, trends analysis for seasonal and annual average maximum and minimum temperatures in most stations exhibited a positive significant trend (Figure 3 and Figure 4). Nevertheless, in the central part of the country for all seasons (Singida and Tabora) depicted a decreasing trend, while Singida had a significant negative trend. However, during MAM Handeni observed a significant decreasing trend (Figure 3(a)).

For the annual scale, Musoma station had an insignificant decreasing trend. The MK results of minimum temperature during the study period presented in (Figure 4) show that during growing season 18/20 stations observed an increasing trend, in which three stations (Tabora, Sumbawanga, and Mahenge) have an insignificant positive trend (Figure 4(a)) while two stations (Singida and Songea) have an insignificant negative trend.

During short rains season all stations showed a positive trend in which four stations (Singida, Tabora, Sumbawanga, and Songea) depicted an insignificant increasing trend (Figure 4(b)). As for the annual scale, results show that 19/20 stations had a positive trend where one station (Singida) observed to have an insignificant increasing trend (Figure 4(c)) while Songea showed an insignificant decreasing trend. The minimum temperature is increasing at a higher rate over
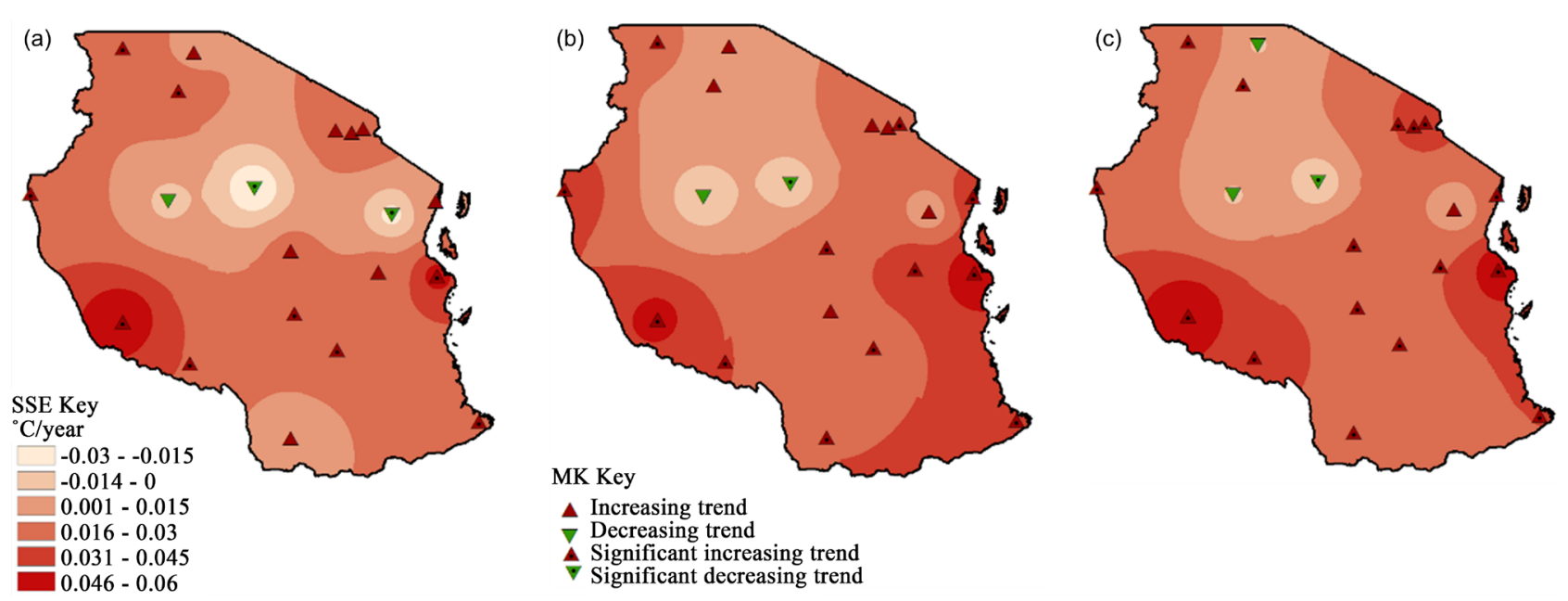

Figure 3. Spatial distribution trend in Maximum temperature; for (a) MAM, (b) OND, and (c) annual scale. The green (red) triangles display a decreasing (increasing) trend, whereas the center dotted characterizes a significant trend at $95 \%$ confidence level. The background color shows the maximum temperature magnitude. 

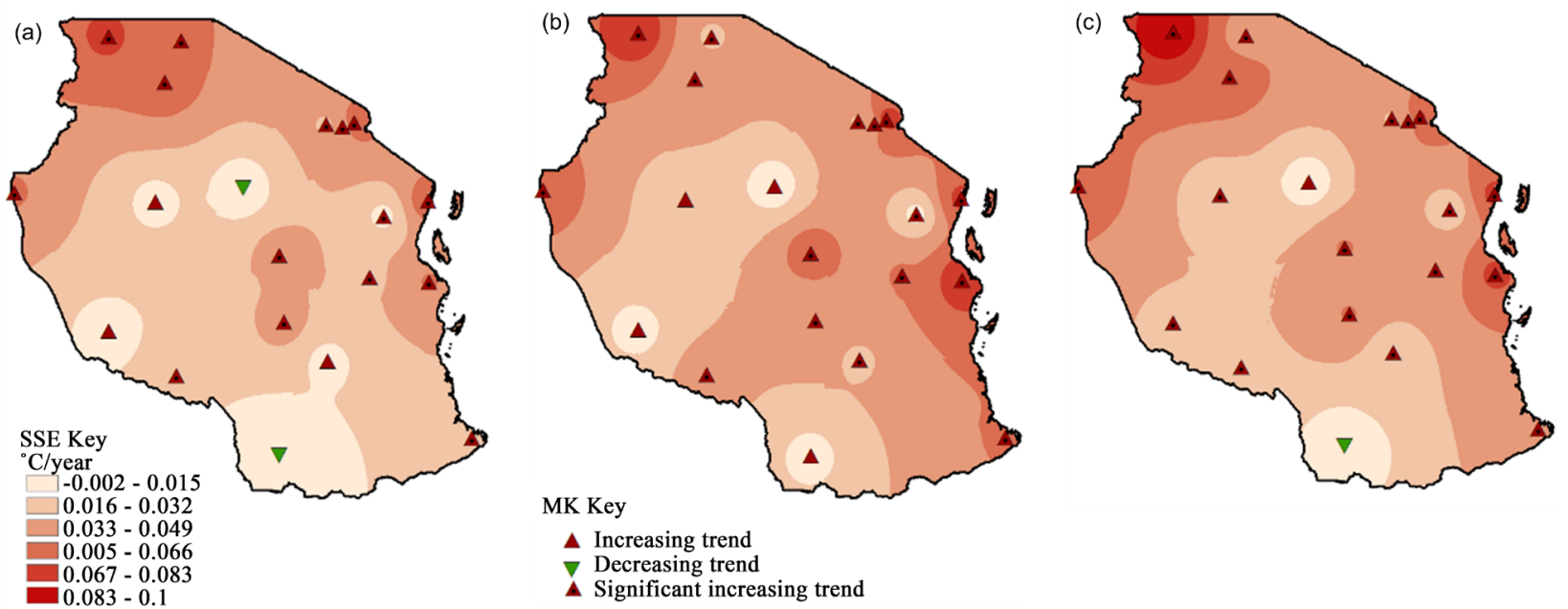

Figure 4. Spatial distribution trend in Minimum temperature; for (a) MAM, (b) OND, and (c) annual scale. The green (red) triangles display a decreasing (increasing) trend, whereas the center dotted characterizes a significant trend at a $95 \%$ confidence level. The background color shows the minimum temperature magnitude.

the country as compared to the maximum temperature (Figure 3 and Figure 4). The highest increase in maximum temperatures was observed in the annual scale $\left(0.6^{\circ} \mathrm{C} /\right.$ year $)$ and the least increase in MAM $\left(0.58^{\circ} \mathrm{C} /\right.$ year $)$. The minimum temperature is increases more in the annual scale $\left(0.83^{\circ} \mathrm{C} /\right.$ year $)$ and with slightly low increase in MAM season $\left(0.68^{\circ} \mathrm{C} /\right.$ year $)$.

\subsection{Maize Yield Characteristics}

Maize plants can grow in areas receiving rainfall amounts in the range of 380 $500 \mathrm{~mm}$ [35]. This climate limiting factors have been weakened by introduction of drought-tolerant varieties by Tanzania Agricultural Research Institute (TARI) that suite the ASALs region. Analysis indicates that area under maize production is increasing at a rate of 1.02 hectare per year while maize yield is decreasing at a rate of 0.004 tons/ha/year (Figure 5(a)). The country receives below-average yield and more years of extremely high yield as evidenced by whiskers of the box plot despite having gaussian distribution (mean and median) of 1.68 tons/ha, 1.53 tons/ha, respectively (Figure 5(b)).

\subsection{Impacts of Hydroclimate Variability during the Growing Period}

Seasonal growing hydroclimates are considered because they have high explanatory power to maize yield anomalies as compared to non-growing period. During the long rains season, rainfall is positive correlated at $r=0.67$, at $p \leq 0.05$. An increase in maximum temperature negatively affects the yield as indicated by negative correlation $r=-0.52$, at $p \leq 0.05$. While accelerating minimum temperature has increase maize yield especially at the high-altitude regions where low temperature has been a limiting factor, though the relationship is not significant, $r=-0.1$, at $p<0.05$. Temperature range has significant negative impacts on maize yield at $r=-0.56$, at $p<0.05$. The interaction of temperature and rainfall 
during growing period affects specific change in yield though their effects are not addictive since they offset each other (Figure 6). The time of occurrence of
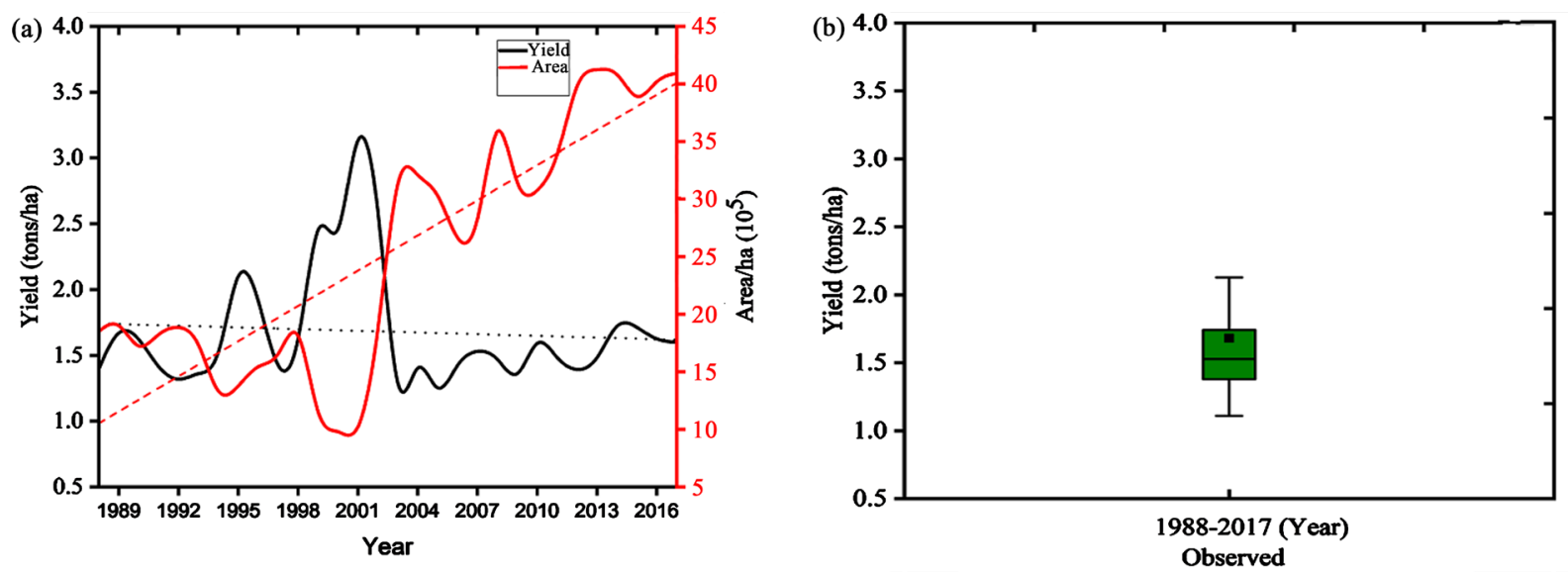

Figure 5. The relationship between yield (tons/ha) and area under cultivation on the left side and the box plot (right) indicates the distribution of the yield. The 25th and 75th percentile demarcates the box, the middle line depicts the median, the rectangle small box inside the box plot depicts the average, while the whiskers represents to the extreme.
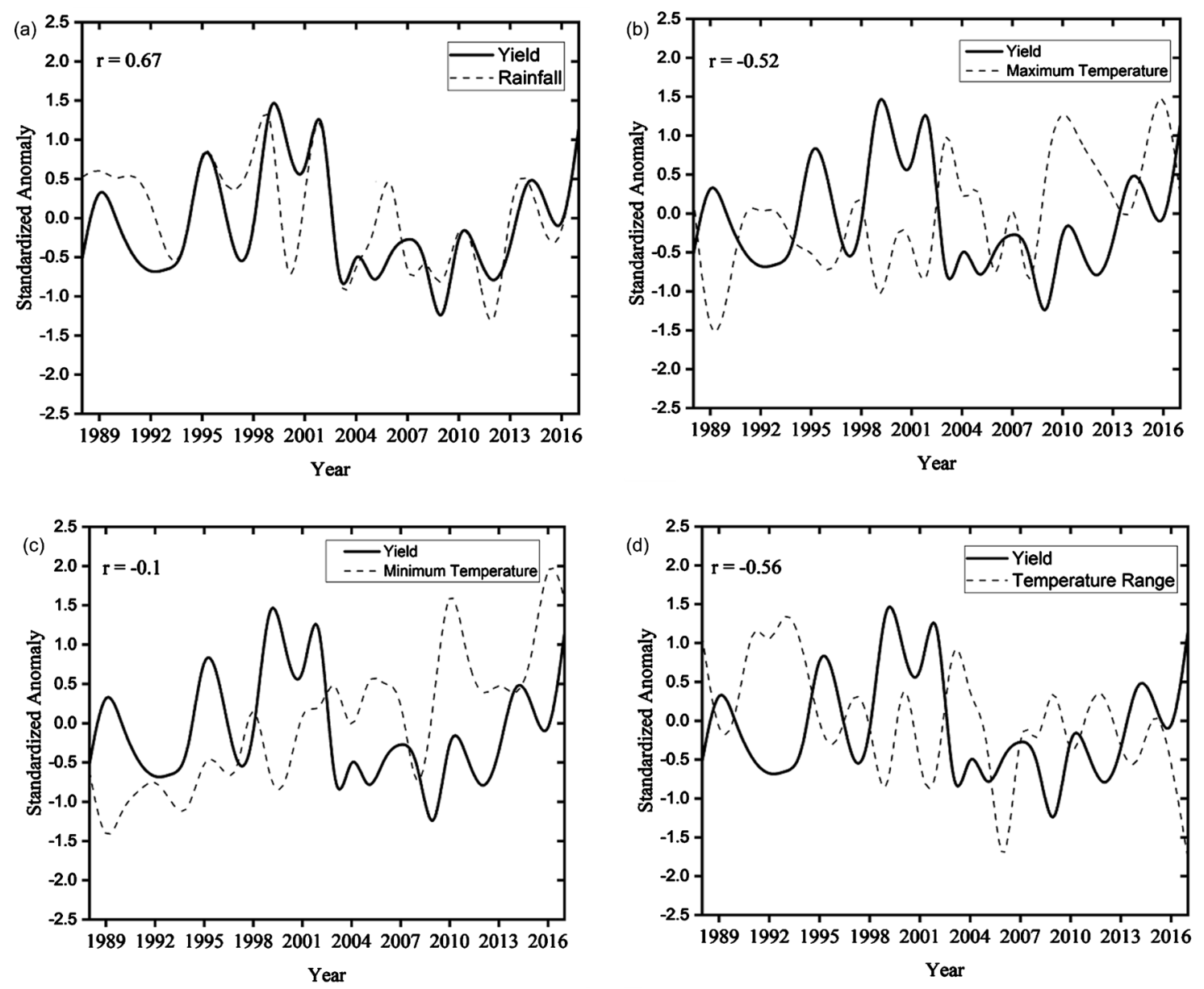

Figure 6. Time series of seasonal characteristics of standardized yield in relation to (a) Standardized rainfall, (b) Standardized maximum temperature, (c) Standardized minimum temperature and (d) Standardized temperature range from 1988-2017 during long rains season, $\mathrm{r}$ is the correlation coefficient. 
these hydroclimates stress is very crucial if temperature is past the threshold, no significant change can be brought by influence of rainfall.

During Vuli rains there is no significant correlation amid annual maize yield and rainfall, minimum, maximum, and temperature range, hence not considered in this analysis.

\subsection{Climate Anomalies during High/Low Maize Yield Years}

\subsubsection{Analysis of Extremes Maize Yield}

Variability of agriculture production is caused by occurrence of extremes in the distribution that leads to climate variability. The identification of high/low years were based on the standardized anomalies; i.e. +1 and -1 , respectively. Results show that, four years of above average and two years of below average yield were observed. The wettest years (>1.0) were 1995, 1999, 2001 and 2002; worst drought was 2003 and 2005 (Figure 7). Remarkably, during the El Niño years 1997/1998, below mean climatological maize yield were recorded. This can be linked to damages caused by excessive rainfall during that extreme ENSO event.

\subsubsection{Characteristics of climate Anomalies during High/Low Maize Yield Years}

Since climate variability has a significant influence on maize yield, it's necessary to examine weather characteristics during extreme maize yield periods. Mean seasonal cycles of rainfall, maximum and minimum, temperature ranges were calculated during those years with respect to the climatological mean. Results show that, high yield years were characterized by increased rainfall during the two growing seasons but more pronounced during the long rains season (MAM) (Figure 8(a)). At the same time maximum temperature was below the climatological mean, while minimum temperature increased above the long-term mean. Additionally, temperature range was below the climatological mean in both seasons.

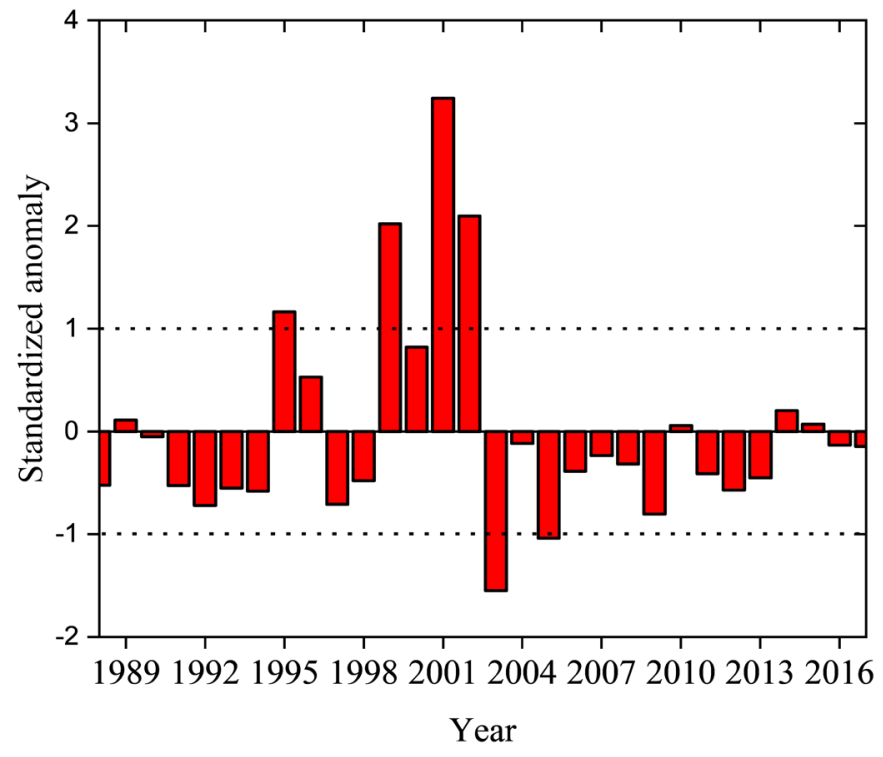

Figure 7. Identification of anomalous high/low maize yield years. 

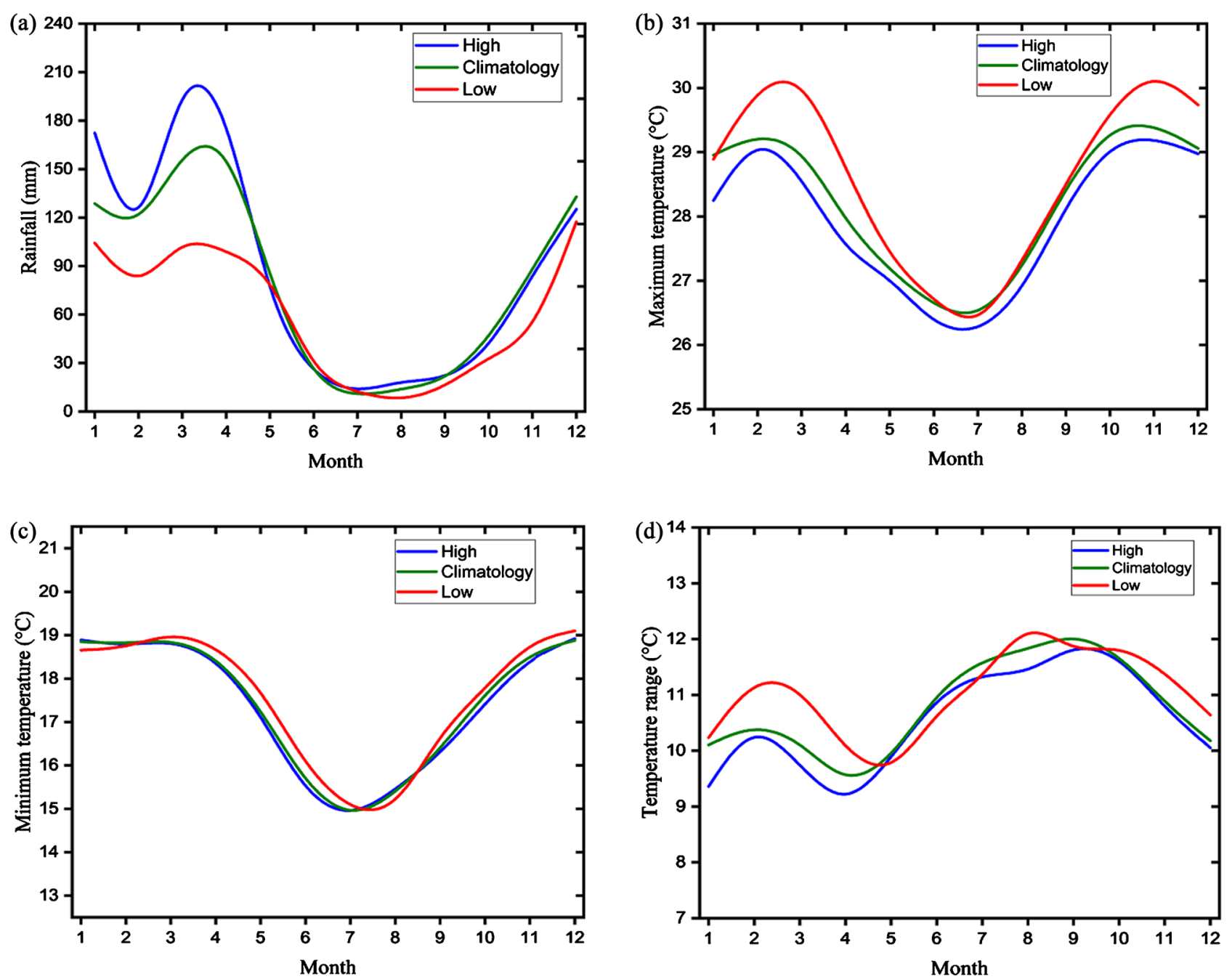

Figure 8. Mean annual cycles of hydroclimate during high/low maize yield years for; (a) Rainfall (mm), (b) Maximum temperature $\left({ }^{\circ} \mathrm{C}\right),(\mathrm{c})$ Minimum temperature $\left({ }^{\circ} \mathrm{C}\right)$, and $(\mathrm{d})$ Temperature range $\left({ }^{\circ} \mathrm{C}\right)$.

This climate characteristic made the environment more favorable for maize growth as compared to a normal year, hence anomalous high maize yield.

Anomalous or declined low maize yield years were characterized by a decrease in rainfall throughout the year, coupled with high maximum temperature from March to the rest of growing season, though there were no differences from May-September. The minimum temperature was below climatological mean before the beginning of long rains which indicates a false start of the growing season, and was above climatological mean during the short rains. In high/low yield years, the temperature range differs from the climatology. This coupled impact of the hydroclimate leads to harsh weather that was not conducive for maize growth, hence the reported anomalously or declined low maize. Low yields result from a decrease in rainfall accompanied by high temperature leading to both water and moisture stress to the crop. Conclusively, years with high/low maize yield was associated with rainfall, maximum, minimum, and temperature range that marginally positively deviates from the climatological mean. 


\subsection{Empirical Analysis}

\subsubsection{Relationship between Seasonal Climate Anomalies and National Maize Yield over Tanzania}

Region scale climate change and variability consequences are the main factor that alters maize yield variability in Tanzania. Rainfall amounts and its distribution are very important in the rain-fed agriculture system in Tanzania, since different parts of the country have different rainy seasons. For instance, studies by [36] [37] have reported that increasing temperature and decrease rainfall in East Africa regions affect water availability, food security, and human health. To quantify which climate indexes in which regions in Tanzania has a significant influence on the maize yield, Pearson correlation was performed between the hydroclimate at each synoptic station and national maize yield.

The results of the Pearson correlation between maize yields and hydroclimate parameters indicate that, significant relationship between national maize yield and main maize growing regions have presented in Figure 9. Figure 9 reveals that a stronger relationship indicates that the station is the main contributor to the maize production, and its precipitation/temperature anomalies have a significant influence on maize yield. Moreover, the results indicate that the regions near the coast exhibit significant positive relationship with rainfall, while many other maize growing regions are not significantly impacted by changes in rainfall. This could be due to the fact that, maize is very sensitive to water availability during the growing period, so sufficient rainfall will increase yield. For example, Musoma, Morogoro, Dar es Salaam, and Handeni stations (Figure 9(a)) are major contributors to the maize yield but are extremely hit by rainfall variability. Therefore, adaption techniques including the use of irrigation schemes are very advocated for in those regions.

Indeed, results revealed that MAM seasonal variation in maximum temperature exhibited a significantly strong negative relationship with maize yield, which had significant negative consequences on yield, as evinced by the correlation

(a)

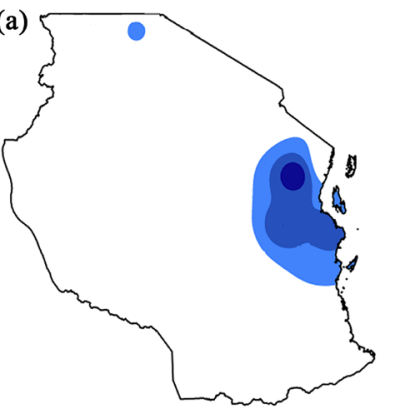

(b)

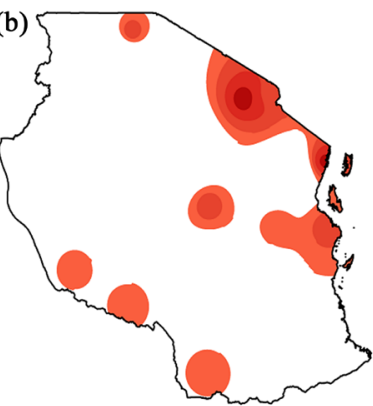

(c)

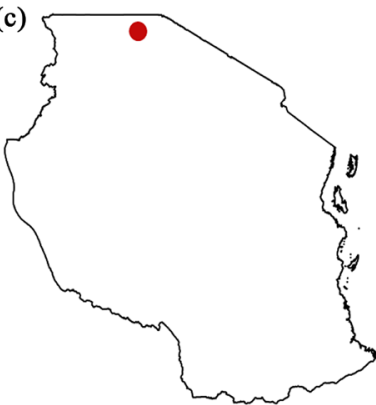

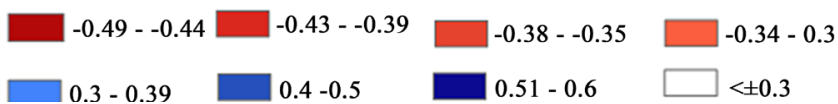

Figure 9. Spatial correlation of (a) MAM rainfall, (b) MAM maximum temperature, and (c) OND maximum temperature anomalies to maize yield, a statistically insignificant relationship amid \pm 0.3 , at $p<0.10$ are not shown. 
factor of $r=-0.49$, at $p<0.1$ (Figure 9(b)). This could also due to the fact that an increase of soil evaporation, which lessens the soil moisture availability for crop growth, and its effects differ from one area to another. For instance, the regions around Lake Victoria basin (Musoma), northeastern part of Tanzania (Arusha and Moshi), central part (Dodoma) and the coastal region (Tanga and Dar es salaam) depicted an anomalous increase of maximum temperature, which resulted in higher stress on maize in the major zones as shown in (Figure 9(b)).

During the short rains season maximum temperature anomalies had significant negative impactions to Tanzania. For example, at Musoma station located in the northern part of the country (Figure $9(c)$ ) had no significant correlation among minimum temperature and maize yield in both seasons.

\subsubsection{Multiple Linear Regression Model}

The results of the fitted multiple linear regression models between the maize yields and climate indices presented in Figure 9 shows that there are three seasonally altering areas that had a significant correlation. The fitted model (Equation (11)) used three climate indices namely, OND maximum temperature $\left(O N D_{t m}\right)$ for Musoma station, MAM maximum temperature $\left(M A M_{t m}\right)$ considered in ten stations of Musoma, Arusha, Moshi, Tanga, Dodoma, Morogoro, Dares salaam, Sumbawanga, Mbeya, and Songea, respectively. Finally, the model used the MAM rainfall $\left(M A M_{\text {rain }}\right)$ averaged at four stations Musoma, Handeni, Morogoro, and Dar es Salaam, respectively. In both seasons, there was no significant correlation between maize yield and minimum temperature at any station, so it was not used in model construction. Also, in fitting the statistical model four assumptions were taken in consideration: 1) the errors are assumed to be independent, 2) the residual is normally distribution, and 3) equal spread of variance, 4) the dependent variable average response is a linear function of each set of predictor values. To evaluate the validity of these assumptions' quantile plots and observation of the residual plot were made and all were adhered on.

The regression model is:

$$
Y=10.582+0.011 M A M_{\text {rain }}-0.159 M A M_{t m}-0.213 O N D_{t m}
$$

$y=$ Predicted maize yield, $t m=$ Maximum temperature.

If the climate variable remains constant on the period mean, the constant term in the equation computes the yield variance. It also accounts for other factors like land management practices, such as fertilization, tillage technique, and technological advances which have not been considered in the study. The remaining terms of Equation (11) evaluate the influences of climate changes on maize yield. The specific yield was produced by the interaction between rainfall and temperature during the growing period, so both could account for $58.78 \%$ of maize yield variability. The model's $\mathrm{p}$-value is $3.257 \times 10^{-5} 5$ at $\mathrm{p}<0.05$. Residual standard error was 0.3714 on 26 degrees of freedom, Multiple R-squared: 0.5878, Adjusted R-squared: 0.5403 and F-statistic: 12.36 on 3 and 26 degrees of freedom.

Factors that affect maize yield variability were evaluated to determine which 
parameter is the most important in determining maize output. MAM seasonal rainfall index accounts for $44.1 \%$, while MAM seasonal maximum temperature accounts for $3.1 \%$, and OND seasonal maximum temperature $7.3 \%$ of maize yield variance. Therefore, maize yield variability was highly attributed to MAM seasonal rainfall than temperature. Notably, maize yield is very sensitive to climate change, particularly the effects of changes in rainfall. These results concur with reference [38], who observed that agriculture is becoming more sensitive to climate change/ variability.

The results of the model performance using the Taylor diagram Figure 10 under statistical measures of correlation coefficient $(r)$, unbiased root mean square, and standard deviation (amplitude) shows a standard deviation of no more than one, unbiased root mean square of 0.64 and a correlation coefficient of 0.78 at $p$ $<0.05$ indicating the level of the goodness of fit of the model.

\section{Conclusions and Recommendation}

Climate change that results to climate variability is significantly evidenced over Tanzania. Climate has a significant influence on the maize yield as evidenced from their seasonal relationship. Decreasing rainfall trend accompanied by increasing maximum and minimum temperature trend threatens food security over the whole country as agreed by [39] that projected decrease in rainfall by

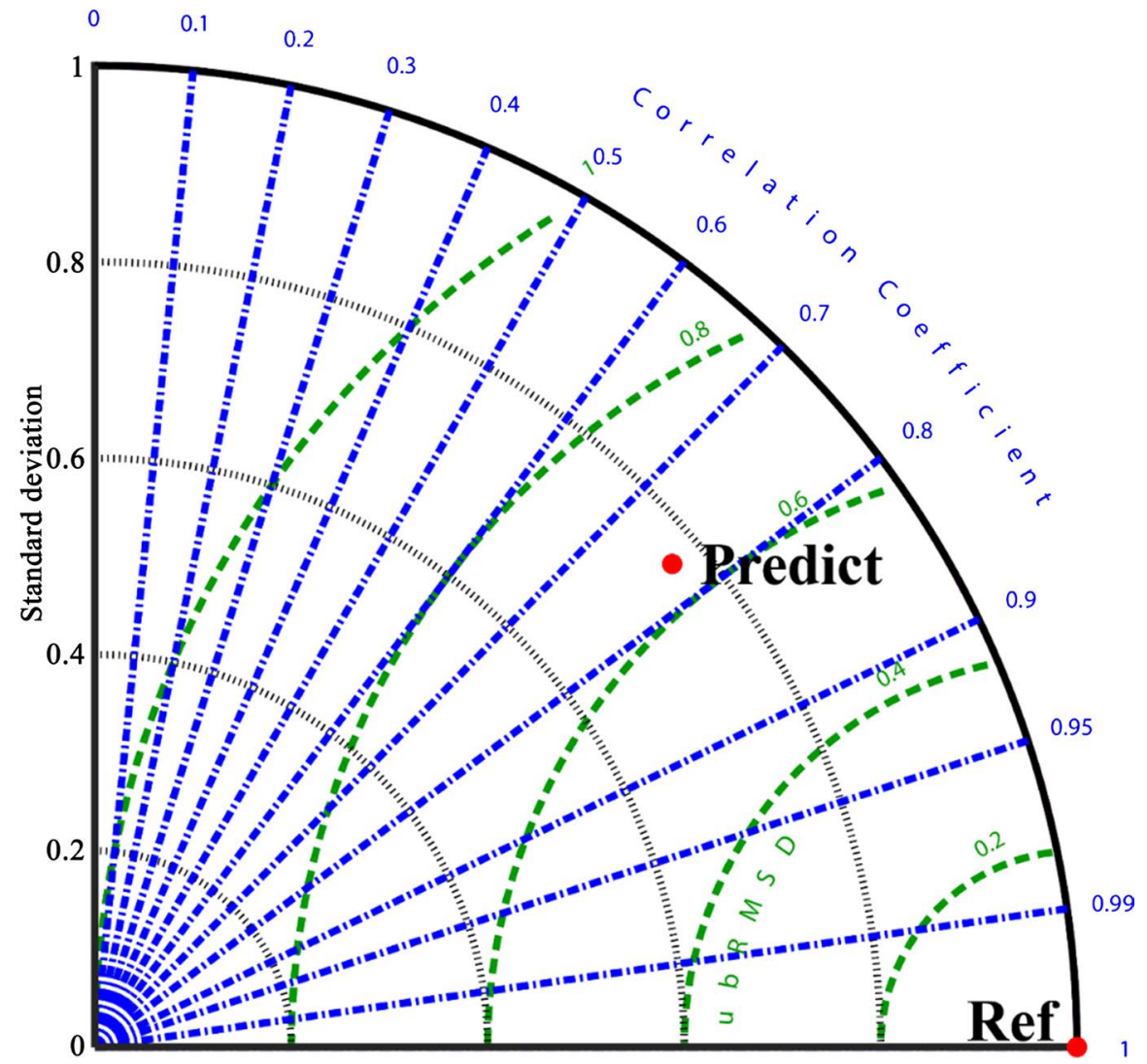

Figure 10. Model evaluation using the Taylor diagram, the red points Predict and Ref show the modeled and the observed yields. 
$10 \%$ mat resulted to a decrease in maize production by up to $3.6 \%$. Decreasing maize yield is observed despite the country producing hybrid breed seeds and increasing the agriculture area. Rainfall exhibits quasi-linear relationship, indicating that either high or low yield is correlated with high or low rainfall anomalies until a threshold is reached above which high rainfall results to decreases in yield. The maximum temperature has a negative correlation and has been shown to be a limiting factor in crop growth when it exceeds the threshold. The temperature range exhibits a significant negative correlation with maize yield.

Mean seasonal rainfall and temperature anomalies in extremes years differ significantly by a margin from climatology. Overall high rainfall amount resulted in high yield if it was not accompanied by maximum temperature beyond threshold since they offset each other. The maximum temperature has great influences on both extremes of maize yield. During low yields years, decreased rainfall was accompanied by high temperature leading to both water and moisture stress on the crop. Mean maize yield over the study period was 1.68 tons per hectare and significantly decreasing at a rate of 0.004 ones/hectare/year at $\mathrm{p} \leq$ 0.05 .

Empirical results show that $58.78 \%$ of maize yield variability is linked to interaction between rainfall and temperature during the growing period, MAM seasonal rainfall index is the most important climate variable as it can account to $44.1 \%$, followed by OND seasonal maximum temperature that accounts to $7.3 \%$ and the least is MAM seasonal maximum temperature accounting to $3.1 \%$ of the total yield variance.

To have a country with food security, priority should be given to different adaption and mitigation strategies on a reliable and understanding of the key agricultural area. ASAL farmers are suggested to move to more drought-tolerant maize varieties and other crops such as sorghum, which are more drought-resistant as compared to maize. Altering of livelihood from agriculture to livestock keeping as a source of income and food is heartened. Thus, the study suggests or recommends for more studies to be conducted in all the four frameworks of food security and considering the limitation of this study, i.e. planting date/biofix/rate, farm management information, and the cultivar used.

\section{Acknowledgements}

The author would like to thanks all that made this paper for publication, for their valuable contributions. Among others, the World Meteorological Organization (WMO) for financial support in the Master degree programme, the University Information science and Technology (NUIST) and the Tanzania Meteorological Authority (TMA).

\section{Conflicts of Interest}

The authors declare no conflicts of interest regarding the publication of this paper. 


\section{References}

[1] Osima, S.E., Indasi, V., Zaroug, M.A.H., Edris, H., Gudoshava, M., Misiani, H., Nimusiima, A., Anyah, R., Otieno, G., Ogwang, B. and Jain, S. (2018) Projected Climate over the Greater Horn of Africa under $1.5^{\circ} \mathrm{C}$ and $2^{\circ} \mathrm{C}$ Global Warming. Environmental Research Letters, 13, Article ID: 065004. https://doi.org/10.1088/1748-9326/aaba1b

[2] Khan, S.A., Kumar, S., Hussain, M.Z. and Kalra, N. (2009) Climate Change, Climate Variability and Indian Agriculture. In: Singh, S.N., Ed., Climate Change and Crops, Springer, Berlin, Heidelberg, 19-38. https://doi.org/10.1007/978-3-540-88246-6 2

[3] TMA Book (2019-2020) Statement on the Status of Tanzania Climate in 2019. Tanzania Meteorological Authority, city.

[4] IPCC (Intergovernmental Panel on Climate Change) (2007) Climate Change 2017: Impacts, Adaptions and Vulnerability. Intergovernmental Panel on Climate Change, Geneva.

[5] IPCC (Intergovernmental Panel on Climate Change) (2012) Managing the Risks of Extreme Events and Disasters to Advance Climate Change Adaptation. Special Report of the Intergovernmental Panel on Climate Change. Cambridge University Press, Cambridge, $582 \mathrm{p}$.

[6] IPCC (Intergovernmental Panel on Climate Change) (2013) Climate Phenomena and Their Relevance for Future Regional Climate Change. In: Stocker, T.F., Qin, D., Plattner, G.-K., Tignor, M., Allen, S.K., Boschung, J., Eds., Climate Change 2013: The Physical Science Basis, Cambridge University Press, Cambridge, 1217-1308. https://www.ipcc.ch/site/assets/uploads/2018/02/WG1AR5 Chapter14 FINAL.pdf

[7] Akram, N. (2013) Is Climate Change Hindering Economic Growth of Asian Economies? Asia-Pacific Development Journal, 19, 1-18. https://doi.org/10.18356/e7cfd1ec-en

[8] Parry, M.L., Rosenzweig, C., Iglesias, A., Livermore, M. and Fischer, G. (2004) Effects of Climate Change on Global Food Production under SRES Emissions and Socio-Economic Scenarios. Global Environmental Change, 14, 53-67. https://doi.org/10.1016/j.gloenvcha.2003.10.008

[9] Ahmed, S.A., Diffenbaugh, N.S. and Hertel, T.W. (2009) Climate Volatility Deepens Poverty Vulnerability in Developing Countries. Environmental Research Letters, 4, Article ID: 034004. https://doi.org/10.1088/1748-9326/4/3/034004

[10] Nyoro, J. K., Ayieko, M. and Muyanga, M. (2007) The Compatibility of Trade Policy with Domestic Policy Interventions Affecting the Grains Sector in Kenya. Paper Presented at FAO Workshop on Trade and Policy for Food Products Conducive to Development in East Africa, Rome, 1-2 March 2007.

[11] Leff, B., Ramankutty, N. and Foley, J.A. (2004) Geographic Distribution of Major Crops across the World. Global Biogeochemical Cycles, 18, Article No. GB1009. https://doi.org/10.1029/2003GB002108

[12] United Republic of Tanzania (2013) National Agriculture Policy. Ministry of Agriculture Food Security and Cooperatives (MAFSC).

[13] Herrero, M., Ringler, C., van de Steeg, J.A., Thornton, P.K., Zhu, T., Bryan, E. and Notenbaert, A.M.O. (2010) Climate Variability and Climate Change and Their Impacts on Kenya's Agricultural Sector. International Livestock Research Institute, Nairobi.

http://cgspace.cgiar.org/bitstream/handle/10568/2665/Kenya Project\%20Note\%201 final.pdf 
[14] Mumo, L., Yu, J. and Fang, K. (2018) Assessing Impacts of Seasonal Climate Variability on Maize Yield in Kenya. International Journal of Plant Production, 12, $297-$ 307. https://doi.org/10.1007/s42106-018-0027-x

[15] FAO (Food and Agriculture Organization of the United Nations) (2008) Introduction to the Basic Concepts of Food Security. Food and Agriculture Organization of the United Nations, Rome.

[16] Tao, F. and Zhang, Z. (2011) Impacts of Climate Change as a Function of Global Mean Temperature: Maize Productivity and Water Use in China. Climatic Change, 105, 409-432. https://doi.org/10.1007/s10584-010-9883-9

[17] Rowhani, P., Lobell, D.B., Linderman, M. and Ramankutty, N. (2011) Agricultural and Forest Meteorology Climate Variability and Crop Production in Tanzania. Agricultural and Forest Meteorology, 151, 449-460.

https://doi.org/10.1016/j.agrformet.2010.12.002

[18] Barron, J., Rockström, J., Gichuki, F. and Hatibu, N. (2003) Dry Spell Analysis and Maize Yields for Two Semi-Arid Locations in East Africa. Agricultural and Forest Meteorology, 117, 23-37. https://doi.org/10.1016/S0168-1923(03)00037-6

[19] Hastenrath, S., (2001) Variations of East African Climate during the Past Two Centuries. Climatic Change, 50, 209-217. https://doi.org/10.1023/A:1010678111442

[20] Indeje, M., Semazzi, F.H.M. and Ogallo, L.J. (2000) ENSO Signals in East African Rainfall Seasons. International Journal of Climatology, 20, 19-46.

https://doi.org/10.1002/(SICI)1097-0088(200001)20:1\%3C19::AID-JOC449\%3E3.0. CO;2-0

[21] Camberlin, P. and Philippon, N. (2002) The East African March-May Rainy Season: Associated Atmospheric Dynamics and Predictability over the 1968-97 Period. Journal of Climate, 15, 1002-1019. https://doi.org/10.1175/1520-0442(2002)015\%3C1002:TEAMMR\%3E2.0.CO;2

[22] Ogallo, L.J. (1988) Relationships between Seasonal Rainfall in East Africa and the Southern Oscillation. Journal of Climatology, 8, 31-43.

https://doi.org/10.1002/joc.3370080104

[23] Luhunga, P.M., Kijazi, A. L., Chang'a, L., Kondowe, A., Ng'ongolo, H. and Mtongori, H. (2018) Climate Change Projections for Tanzania Based on High-Resolution Regional Climate Models from the Coordinated Regional Climate Downscaling Experiment (CORDEX)-Africa. Frontiers in Environmental Science, 6, Article No. 122. https://doi.org/10.3389/fenvs.2018.00122

[24] Alexandersson, H. (1986) A Homogeneity Test Applied to Precipitation Data. Journal of Climatology, 6, 661-675. https://doi.org/10.1002/joc.3370060607.

[25] Schlenker, W. and Lobell, D.B. (2010) Robust Negative Impacts of Climate Change on African Agriculture. Environmental Research Letters, 5, Article ID: 014010. https://doi.org/10.1088/1748-9326/5/1/014010

[26] Porter, J.R. and Semenov, M.A. (2005) Crop Responses to Climatic Variation. Philosophical Transactions of the Royal Society B: Biological Sciences, 360, 2021-2035. https://doi.org/10.1098/rstb.2005.1752

[27] Schlenker, W. and Roberts, M.J. (2009) Nonlinear Temperature Effect Indicates Severe Damages to U.S. Crop Yields under Climate Change. Proceedings of the National Academy of Sciences of the United States of America, 106, 15594-15598. https://doi.org/10.1073/pnas.0906865106

[28] Lobell, D.B. and Field, C.B. (2007) Global Scale Climate-Crop Yield Relationships and the Impacts of Recent Warming. Environmental Research Letters, 2, Article ID: 01402. https://doi.org/10.1088/1748-9326/2/1/014002 
[29] Hayelom, B., Chen, Y., Marsie, Z. and Negash, M. (2017) Temperature and Precipitation Trend Analysis over the Last 30 Years in Southern Tigray Regional. (February), 1-11. (Preprint) https://doi.org/10.20944/preprints201702.0014.v1

[30] Fan, X. and Wang, M. (2011) Change Trends of Air Temperature and Precipitation over Shanxi Province, China. Theoretical and Applied Climatology, 103, 519-531. https://doi.org/10.1007/s00704-010-0319-2

[31] Wu, Y., Wang, W. and Wang, G. (2016) Detecting Variation Trends of Temperature and Precipitation for the Dadu River Basin, China. Advances in Meteorology, 2016, Article ID: 2564586. https://doi.org/10.1155/2016/2564586

[32] Sen, P.K. (1968) Estimates of the Regression Coefficient Based on Kendall's Tau. Journal of the American Statistical Association, 63, 1379-1389.

https://doi.org/10.2307/2285891

[33] Gilbert, R.O. (1987) Statistical Methods for Environmental Pollution Monitoring. John Wiley \& Sons, Hoboken.

[34] Hollander, M., Wolfe, D.A. and Chicken, E. (2013) Nonparametric Statistical Methods. Vol. 751, John Wiley \& Sons, Hoboken.

[35] Adamgbe, E.M. and Ujoh, F. (2013) Effect of Variability in Rainfall Characteristics on Maize Yield in Gboko, Nigeria. Journal of Environmental Protection, 4, 881-887. https://doi.org/10.4236/jep.2013.49103

[36] Case, M. (2006) Climate Change Impacts on East Africa. World Wide Fund for Nature, Gland.

[37] Mubaya, C.P., Jalloh, A. and Mogaka, H. (2014) Review of Research and Policies for Climate Change Adaptation in Urban Areas in East Africa. Working Paper 102. https://doi.org/10.13140/RG.2.1.2009.0961

[38] Liang, X.Z., Wu, Y., Chambers, R.G., Schmoldt, D.L., Gao, W., Liu, C. and Kennedy, J.A. (2017) Determining Climate Effects on US Total Agricultural Productivity. Proceedings of the National Academy of Sciences of the United States of America, 114, E2285-E2292. https://doi.org/10.1073/pnas.1615922114

[39] Batho, P., Shaban, N. and Mwakaje, A. (2019) Impacts of Rainfall and Temperature Variation on Maize (Zea mays L.) Yields: A Case Study of Mbeya Region, Tanzania. Archives of Agriculture and Environmental Science, 4, 177-184. https://doi.org/10.26832/24566632.2019.040208 